\title{
Building a Better Antipsychotic: Receptor Targets for the Treatment of Multiple Symptom Dimensions of Schizophrenia
}

\author{
Dennis H. Kim,* Matthew J. Maneen,* and Stephen M. Stahl ${ }^{\dagger}$ \\ *Arbor Scientia, Carlsbad, California 92008, and ${ }^{\dagger}$ Department of Psychiatry, University of California, San Diego, \\ School of Medicine, La Jolla, California 92093
}

\begin{abstract}
Summary: Attempts to develop selective ("magic bullet") drugs for the treatment of schizophrenia have been frustrated by the complex etiology of the disease. The symptomatology of schizophrenia does not appear to arise from a single neurobiological entity, but rather may be derived from pathology at one or more receptor types. This has prompted multifactorial approaches to the development of new therapeutics, as embodied by polypharmacy and an alternative (or augmentative) strategy known as "intramolecular polypharmacy," in which a single drug possesses the capacity to affect multiple receptor types.
\end{abstract}

Atypical antipsychotics are a well-known example of this approach; each atypical possesses a unique portfolio of activities at receptors that may contribute to therapeutic effects (as well as side effects). In this article we present a discussion of some of the receptor targets that are currently thought to mediate symptoms of schizophrenia, as well as their possible implications for the design of future multifunctional antipsychotics. Key Words: Antipsychotics, intramolecular polypharmacy, receptors, negative symptoms, glutamatergic neurotransmission.

\section{INTRODUCTION}

The development of antipsychotics has come full circle, from the development of "dirty" drugs with multiple mechanisms of therapeutic action and side effects, to selective agents with a single therapeutic action, and now back again to multifunctional therapeutics. This progression reflects the development of our understanding of the mechanisms underlying the actions of psychotropic drugs. First-generation antipsychotics were serendipitously discovered, and only after clinical use were the mechanisms of their desirable therapeutic actions deduced and distinguished from the mechanisms of their undesirable side effects. However, attempts to develop selective "magic bullets" that factor out side effects have been frustrated by the complexity of schizophrenia and the fact that the symptomatology of the disease does not appear to arise from a single neurobiological entity. Schizophrenia not only has psychotic features, but negative symptoms, affective symptoms, cognitive symptoms, and probably neurodevelopmental and neurodegenerative aspects as well. Each of these symptom

Address correspondence and reprint requests to: Stephen M. Stahl, M.D., Ph.D., 1930 Palomar Point Way, Suite 103, Carlsbad, CA 92008. E-mail: smstahl@neiglobal.com. dimensions may be derived from pathology at one or more receptor types (FIG. 1).

The absence of a single therapeutic target has perforce prompted a multifactorial approach to treating schizophrenia. One obvious tactic has been polypharmacy, which is the use of two or more drugs to treat multiple symptoms. An alternative (or possibly augmentative) strategy has been "intramolecular polypharmacy," in which a single drug possesses the capacity to affect multiple receptor types. This approach is already embodied in the atypical antipsychotics, each of which has a unique portfolio of activity at receptors that may contribute to therapeutic effects (as well as side effects). Polypharmacy aspires to take advantage of potential synergies among independent therapeutic mechanisms, whether they are present in a single drug or in multiple drugs working in tandem. Unfortunately, there is no "free lunch," and adding more mechanisms almost always means adding more mechanism-related side effects.

The most robust action of any antipsychotic is generally its ability to reduce the positive symptoms of psychosis (e.g., delusions and hallucinations), and these symptoms are often the first targets for treatment of schizophrenia. It is important to note, however, that in 


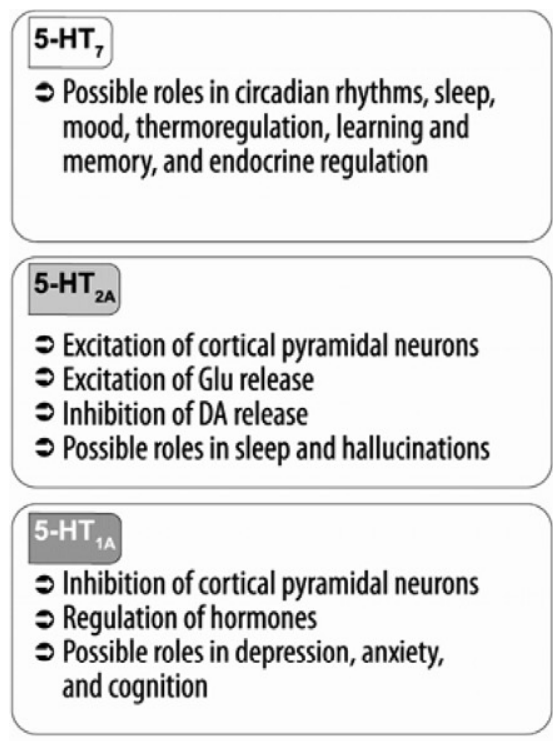

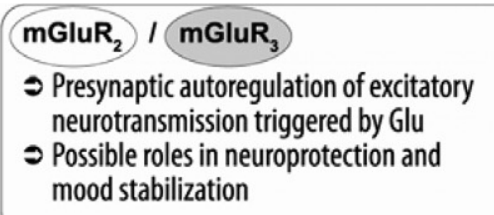
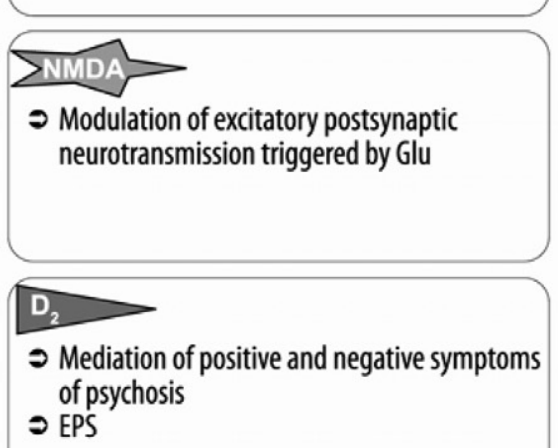

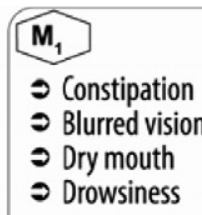

\section{$H_{1}$}

จ Weight gain

$\supset$ Drowsiness

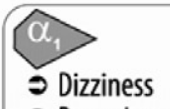

$\rightarrow$ Drowsiness

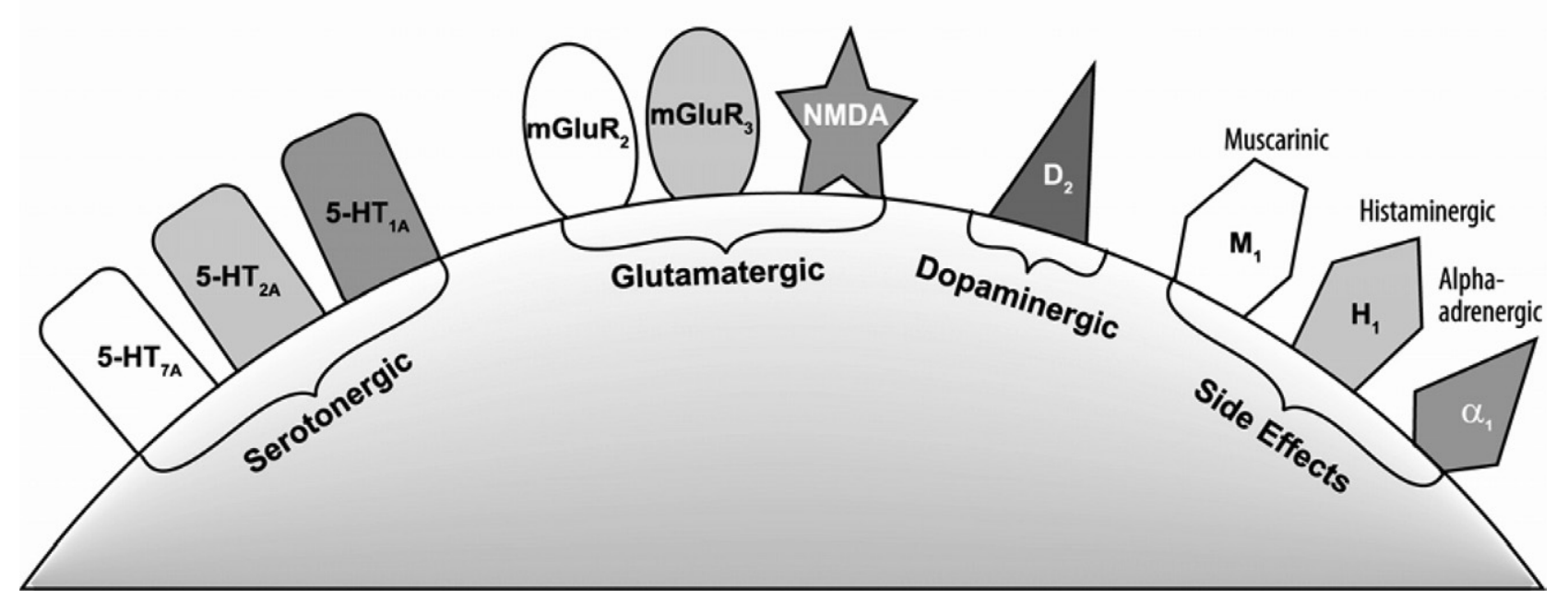

FIG. 1. Potential functions of selected CNS receptors that are currently thought to mediate symptoms of schizophrenia. It is important to recognize that the various symptoms of schizophrenia are now recognized to be not only mediated by specific receptor sites, but localized in unique regions of the brain as well. The functions ascribed to the receptors here are therefore dependent on the location of the specific receptors in the brain. Furthermore, whether therapeutic effects are the result of full or partial agonism, antagonism, or inverse agonism depends on each receptor type. mGluR, metabotropic glutamate receptors; NMDA, ionotropic N-methyl-D-aspartate.

current therapeutic strategies for schizophrenia, the greatest unmet needs are in treatment of negative and cognitive symptoms. In 2006, the National Institute of Mental Health issued a consensus statement that "persistent and clinically significant negative symptoms are an unmet therapeutic need" that should be a focus of future drug development efforts. ${ }^{1}$ In this article we present a forward-looking review of some of the receptor targets that are currently thought to mediate symptoms of schizophrenia, as well as their possible implications for future multifunctional antipsychotics. The framing question to consider for the following discussion is: If an antipsychotic were to be "built" from scratch, what features would be desirable?

\section{$\mathrm{D}_{2}$ OR NOT $\mathrm{D}_{2}$ ?}

Conventional and atypical antipsychotics alike are dopamine $\mathrm{D}_{2}$ antagonists or inverse agonists; when they bind to $D_{2}$ receptors they either inhibit basal activity in the $\mathrm{D}_{2}$ receptor-linked G-protein messenger system (inverse agonism) or have no effect on basal activity (silent antagonism). ${ }^{2,3}$ In both cases, the antipsychotic blocks postsynaptic receptors and normalizes the hyperactivity theoretically arising from excessive dopamine at the synapse; the result of the hypothetical normalization in the mesolimbic dopamine pathway is a reduction in positive psychotic symptoms. Beyond the rubric of $\mathrm{D}_{2}$ antagonism/inverse agonism, however, there is no consensus as 
to what intrinsic characteristics define an antipsychotic. Kapur and Seeman ${ }^{4}$ have proposed that atypicality arises in antipsychotics that bind to $\mathrm{D}_{2}$ postsynaptic receptors with relatively low affinity, and therefore more rapid dissociation rates. Theoretically, such an agent is able to occupy $\mathrm{D}_{2}$ receptors long enough to exert an antipsychotic action, but not long enough for extrapyramidal symptoms (EPS), prolactin elevation, or secondary negative symptoms to develop. Currently, it is still unclear how long an atypical must reside at $\mathrm{D}_{2}$ receptors to achieve the balance of therapeutic efficacy and minimal EPS. ${ }^{5}$ Although rapid dissociation from the $\mathrm{D}_{2}$ receptor in vitro is a good predictor of low EPS potential in patients, this "hit-and-run" action may not be acceptable as a general mechanism of atypicality because it does not account for the fact that the atypical antipsychotics olanzapine, risperidone, and ziprasidone all have high $\mathrm{D}_{2}$ affinities and slow dissociation rates from the receptor. ${ }^{6,7}$

Another $\mathrm{D}_{2}$-centered mechanism that has gained currency is dopamine $D_{2}$ partial agonism. In the spectrum of pharmacological actions that range from agonism to inverse agonism, the actions of dopamine partial agonists (DPAs) on $\mathrm{D}_{2}$ receptors lie somewhere between full agonism and silent antagonism (FIG. 2). As their name implies, DPAs activate the $\mathrm{D}_{2}$ receptor's second messen- ger system, but in a manner that is less than the activation produced by full agonists (including dopamine itself). Pharmacologically, DPAs activate at low dopaminergic tone and inhibit at high dopaminergic tone. In other words, in the presence of excessive agonist action by dopamine, DPAs reduce signal transduction in the $\mathrm{D}_{2}$ linked G-protein messenger system. Conversely, when dopamine is deficient, DPAs increase $\mathrm{D}_{2}$-receptor-mediated signal transduction. ${ }^{8}$ By mediating between the extremes of hyperdopaminergia and hypodopaminergia, partial agonists are thus sometimes called "stabilizers." ${ }^{, 10}$

Partial agonism has unique functional and clinical consequences. In theory, DPAs used to treat schizophrenia reduce $D_{2}$ hyperactivity in mesolimbic dopamine neurons to a degree that is sufficient to exert an antipsychotic action on positive symptoms, even though they do not completely shut down $\mathrm{D}_{2}$ receptors as do conventional antipsychotics. At the same time, DPAs reduce dopamine activity in the nigrostriatal system to an extent that is insufficient to induce EPS. However, clinical experience with DPAs suggests that only those that are close to the antagonist end of the spectrum may have antipsychotic efficacy. For example, the partial agonist OPC 4293 developed by Otsuka Pharmaceutical was

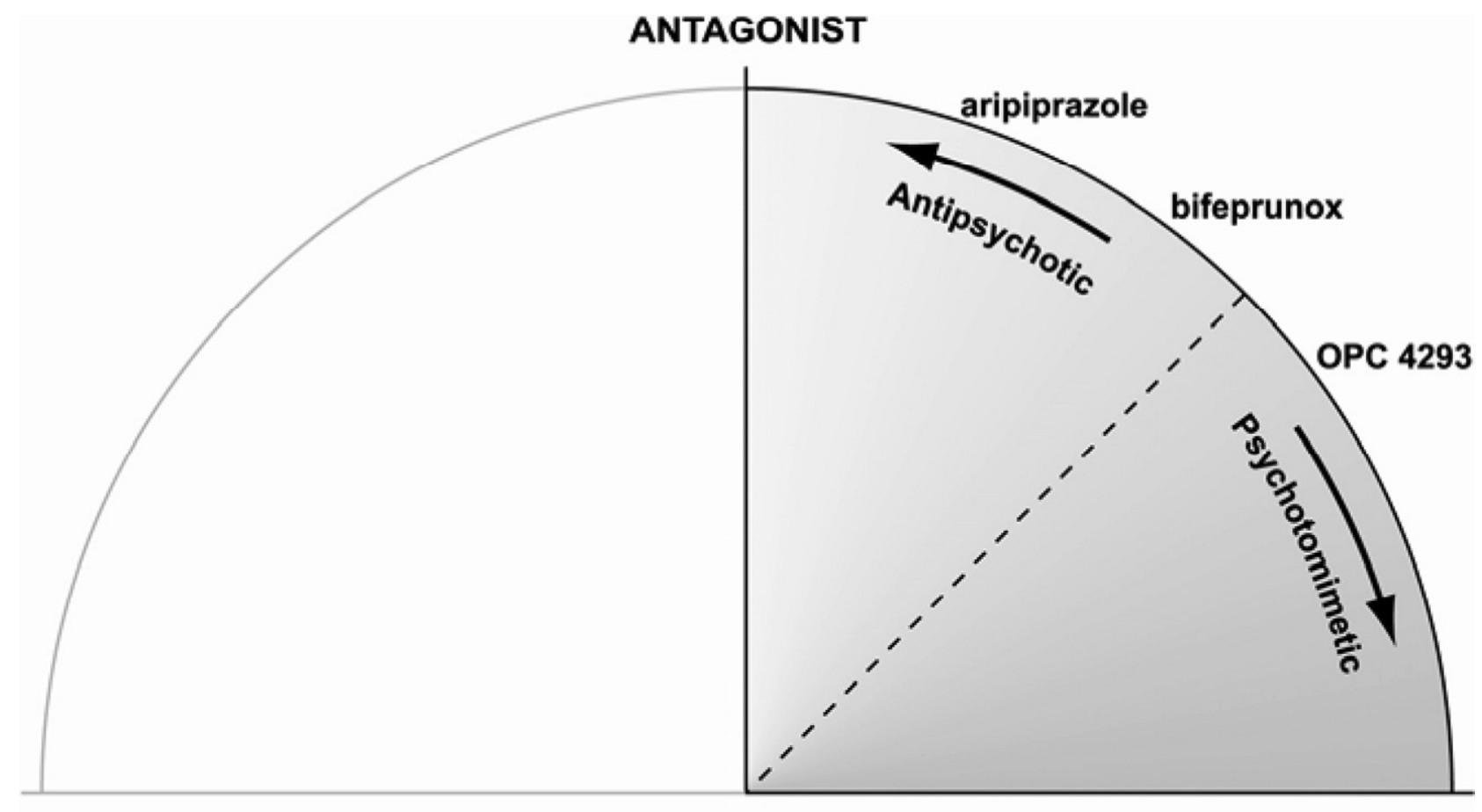

INVERSE AGONIST

AGONIST

FIG. 2. The Agonist Spectrum. Naturally occurring neurotransmitters stimulate receptors and thus are agonists. Some drugs also stimulate receptors and therefore are agonists as well. It is possible for drugs to stimulate receptors to a lesser degree than the natural neurotransmitter; these are called partial agonists or stabilizers. Antagonists have no intrinsic activity of their own in the absence of an agonist; for this reason, antagonists are sometimes called "silent." Inverse agonists, on the other hand, have the opposite effect as agonists. With respect to $D_{2}$ partial agonists (DPAs), some DPAs have too much agonism and may actually be psychotomimetic; an example is the agent OPC 4293. In contrast, partial agonists that are closer to the antagonist range of the spectrum are thought to have more favorable antipsychotic profiles; examples include aripiprazole and bifeprunox). 
found to be too activating, improving negative symptoms but worsening positive symptoms. ${ }^{8}$ Another example of a DPA that is "too full" is bifeprunox (developed by Solvay Pharmaceuticals), which exhibited a slow onset of action due to activating side effects and was associated with nausea and vomiting. ${ }^{8}$ Furthermore, bifeprunox showed no significant efficacy at high doses, whereas efficacy at lower doses was inferior to that of a $D_{2}$ antagonist (risperidone); accordingly, bifeprunox was given a nonapproval by the Food and Drug Administration. ${ }^{8}$

On the other hand, another Otsuka compound, aripiprazole, was found to be "less full" as a $\mathrm{D}_{2}$ partial agonist and has demonstrated effectiveness in treating psychotic symptoms as well as symptoms of acute mania. Actions at serotonin receptors may also contribute to the clinical properties of aripiprazole, but are not as potent as aripiprazole's actions at dopamine receptors, and may only be relevant at higher doses. ${ }^{2,11,12}$ Aripiprazole can still be activating in some patients, however, and unlike $\mathrm{D}_{2}$ antagonists, aripiprazole can show an inverted U-shaped dose response for its antipsychotic actions, consistent with partial agonist actions at $\mathrm{D}_{2}$ receptors. $^{8}$ In fact, dosing of aripiprazole for use in augmenting antidepressants in major depression may be even lower than the ideal dose of aripiprazole for use as an antipsychotic, possibly optimizing its agonist rather than its antagonist actions. ${ }^{8,13,14}$ Aripiprazole is apparently most effective for depression at very low doses $(<10 \mathrm{mg})$, and perhaps most effective for mania and psychosis at higher doses $(>10 \mathrm{mg})$, which suggests the possibility that increasing receptor activation at low doses may be what is needed in depression, while blocking at high doses may be what is needed in psychosis.

In summary, with respect to actions at the $\mathrm{D}_{2}$ receptor, there are theoretically several ways in which an antipsychotic can have efficacy in treating positive symptoms. The antipsychotic can be an antagonist, inverse agonist, or partial agonist. Full antagonism or full inverse agonism may come at the price of EPS, hyperprolactinemia, and negative symptoms, unless the mitigating influence of $5-\mathrm{HT}_{2 \mathrm{~A}}$ antagonism is also present (see as follows). Partial agonism may provide an intermediate effect, as long as the action falls closer to silent antagonism than to full agonism on the agonist spectrum. In general, the closer the partial agonist is to the full agonist end of the spectrum, the less effective it becomes as an antipsychotic, the more difficult it is to find the optimal dose, and the more activating and psychotomimetic the drug becomes. ${ }^{2,8}$ Lastly, "hit-and-run" receptor binding involves the drug occupying $D_{2}$ receptors long enough to have an antipsychotic effect, but not long enough for EPS or other adverse effects to arise.

\section{TUNING DOPAMINE OUTPUT WITH 5-HT ${ }_{2 A}$}

As we have discussed, therapeutic agents for schizophrenia must target dysfunction in neurotransmission simultaneously in various brain regions; the challenge lies in balancing multiple, potentially competing therapeutic needs. For example, the treatment of positive psychotic symptoms requires a reduction of dopamine hyperactivity in the mesolimbic dopamine pathway. Unfortunately, a pure $\mathrm{D}_{2}$ antagonist will act indiscriminately at $\mathrm{D}_{2}$ receptors throughout the brain, and in so doing will give rise to unwanted hypoactivity in other dopamine pathways. In this manner, in the mesocortical dopamine pathways to the dorsolateral prefrontal and ventromedial prefrontal cortices, $\mathrm{D}_{2}$ antagonism may produce negative, cognitive, and affective symptoms. As pure $\mathrm{D}_{2}$ antagonists, conventional antipsychotics face a conundrum of "robbing Peter to pay Paul." Therefore, efficacy in treating positive symptoms comes at the price of negative symptom exacerbation and side effects.

The "multifunctionality" of atypicals offers a solution to the problem by way of 5- $\mathrm{HT}_{2 \mathrm{~A}}$ antagonism. Serotonergic neurons that innervate dopaminergic neurons modulate dopamine release via somatodendritic and axodendritic $5-\mathrm{HT}_{2 \mathrm{~A}}$ receptors on dopamine neurons. Antagonism of these $5-\mathrm{HT}_{2 \mathrm{~A}}$ receptors can stimulate dopamine release in certain brain areas, including the prefrontal cortex and the striatum. Therefore, antipsychotics with both $\mathrm{D}_{2}$ and $5-\mathrm{HT}_{2 \mathrm{~A}}$ antagonist properties have the ability to not only decrease dopamine activity by blocking $\mathrm{D}_{2}$ receptors, but also increase dopamine release by blocking $5-\mathrm{HT}_{2 \mathrm{~A}}$. The latter action thus mitigates to some extent the absolute blockade associated with pure $\mathrm{D}_{2}$ antagonism. Which action predominates is the subject of intense current investigation and appears to be specific to different regions of the brain. It is also still unclear whether the activity at $5-\mathrm{HT}_{2 \mathrm{~A}}$ receptors is antagonism or inverse agonism.

Despite the questions surrounding the $5-\mathrm{HT}_{2 \mathrm{~A}}$ receptor and its precise role in the mechanism of action of antipsychotics, it is already clear that the addition of 5- $\mathrm{HT}_{2 \mathrm{~A}}$ antagonist properties to $\mathrm{D}_{2}$ antagonist properties yields a very different type of drug (i.e., an atypical antipsychotic with therapeutic actions not only on positive symptoms but also on negative, cognitive, and affective symptoms, with a significant reduction in the incidence of EPS and hyperprolactinemia). In essence, the $5-\mathrm{HT}_{2 \mathrm{~A}}$ antagonism of atypical antipsychotics can be conceptualized as "fine tuning" dopamine output in malfunctioning neuronal circuits. Clinicians can exploit these properties by individualizing drug selection and dosage to individual patients, since the exact balance of 5- $\mathrm{HT}_{2 \mathrm{~A}}$ antagonism versus $\mathrm{D}_{2}$ antagonism differs between drugs, regions of the brain, and, indeed, between patients. 


\section{5-HT ${ }_{1 \mathrm{~A}}$ : FULL OR PARTIAL AGONISM?}

Another pharmacological mechanism that may contribute to the therapeutic profile of antipsychotics is the ability of some agents to act at $5-\mathrm{HT}_{1 \mathrm{~A}}$ receptors, either as full agonists or partial agonists (serotonin partial agonists). The regulatory effect of $5-\mathrm{HT}_{1 \mathrm{~A}}$ receptors on dopamine release can be thought of as the converse of the influence exerted by $5-\mathrm{HT}_{2 \mathrm{~A}}$ receptors, whereas $5-\mathrm{HT}_{2 \mathrm{~A}}$ agonism acts as a dopamine brake and $5-\mathrm{HT}_{1 \mathrm{~A}}$ agonism acts as a dopamine accelerator. Activation of $5-\mathrm{HT}_{1 \mathrm{~A}}$ autoreceptors disinhibits dopamine release; in the striatum this action lessens hypodopaminergia resulting from $\mathrm{D}_{2}$ blockade and theoretically reduces the risk of EPS, whereas in the pituitary the same action potentially lowers the risk of hyperprolactinemia. In a similar vein, enhanced dopamine release in the prefrontal cortex could potentially improve negative, cognitive, and affective symptoms. ${ }^{15}$ Thus, $5-\mathrm{HT}_{1 \mathrm{~A}}$ agonism has similar net effects as $5-\mathrm{HT}_{2 \mathrm{~A}}$ antagonism. In principle, if the two effects were co-present in a single pharmacological entity, the resulting therapeutic actions of the agent could be additive or synergistic. ${ }^{2}$

Currently, there is debate as to whether the ideal 5- $\mathrm{HT}_{1 \mathrm{~A}}$ actions are agonist, partial agonist, or antagonist. Postsynaptic 5- $\mathrm{HT}_{1 \mathrm{~A}}$ receptors in the cortex are most concentrated on the pyramidal neurons of the cortex and hippocampus, which suggests a role of the receptor in cognitive function. ${ }^{16}$ However, conflicting data have emerged from clinical experiments on the effects of serotonin partial agonists on cognitive function. For example, Sumiyoshi et al. ${ }^{17}$ administered the serotonin partial agonists tandospirone as an adjunctive treatment to patients with schizophrenia who were receiving stable doses of typical antipsychotics and found that executive function and verbal memory were significantly improved in patients receiving tandospirone over patients who did not receive the drug. On the other hand, Yasuno et al. ${ }^{18}$ found that the administration of tandospirone dose dependently impaired explicit verbal memory while leaving other cognitive functions intact, although the subjects in this experiment were healthy volunteers with no neuropsychiatric disorders. The results of preclinical studies in animals are also divided on the question of whether 5-HT ${ }_{1 \mathrm{~A}}$ agonism or antagonism enhances cognition. ${ }^{19}$ In any event, the net long-term consequences of antagonism and agonism may be similar since antagonists block and chronic agonists downregulate $5-\mathrm{HT}_{1 \mathrm{~A}}$ receptors. ${ }^{2}$

\section{5-HT $2 \mathrm{C}:$ AGONIST OR ANTAGONIST?}

Serotonin $5-\mathrm{HT}_{2 \mathrm{C}}$ receptors are able to tonically regulate dopamine release via terminal receptors in the mesolimbic and nigrostriatal pathways. ${ }^{20} 5-\mathrm{HT}_{2 \mathrm{C}}$ receptors are also found at high density on cell bodies in the ventral tegmentum where they are believed to tonically inhibit dopamine release from dopaminergic neurons projecting to the frontal cortex. ${ }^{21}$ Therefore, $5-\mathrm{HT}_{2 \mathrm{C}}$ presents an intriguing but challenging target for therapeutics (i.e., agonism at $5-\mathrm{HT}_{2 \mathrm{C}}$ in the mesolimbic dopamine pathway may reduce dopaminergic transmission and improve positive symptoms of schizophrenia). However, a concern is that dopaminergic suppression via $5-\mathrm{HT}_{2 \mathrm{C}}$ agonism in the mesocortical pathway could potentially worsen cognition, ${ }^{22}$ whereas, in the nigrostriatal pathway the same action might cause EPS. ${ }^{23-25}$ On the other hand, $5-\mathrm{HT}_{2 \mathrm{C}}$ antagonism at inhibitory gamma-aminobutyric acid (GABA) interneurons in the brain stem may be expected to reduce depression and improve cognition by disinhibiting dopamine and norepinephrine release in the prefrontal cortex. ${ }^{2,26}$

Receptors associated with weight gain are $\mathrm{H}_{1}$ histamine receptors and $5-\mathrm{HT}_{2 \mathrm{C}}$ receptors in the hypothalamus. When these receptors are blocked, particularly at the same time, patients may experience enhanced appetite in hypothalamic eating centers, and this increase in appetite may lead to weight gain. Antipsychotics associated with the greatest degree of weight gain are those that have the most potent antagonist actions simultaneously at $\mathrm{H}_{1}$ and $5-\mathrm{HT}_{2 \mathrm{C}}$ receptors.

Features such as the ones we have just described underscore the fact that there is no consensus yet on the ideal actions of antipsychotics at $5-\mathrm{HT}_{2 \mathrm{C}}$ receptors, as with $5-\mathrm{HT}_{1 \mathrm{~A}}$ receptors. $5-\mathrm{HT}_{2 \mathrm{C}}$ agonists and antagonists both present potential rewards as well as pitfalls.

\section{5-HT ${ }_{7}$ : THERAPEUTIC POSSIBILITIES}

Serotonin $5-\mathrm{HT}_{7}$ receptors were discovered only 15 years ago, ${ }^{27-29}$ and their physiological role is still being elucidated. The relatively high density of $5-\mathrm{HT}_{7}$ in the limbic and thalamocortical regions hints at a possible role of the receptor in mediating depressive disorders. Downregulation of $5-\mathrm{HT}_{7}$ has been observed after chronic antidepressant treatment, ${ }^{30}$ and several antipsychotics and antidepressants (such as clozapine, zotepine, risperidone, pimozide, and fluoxetine) have been found to bind with high affinity at $5-\mathrm{HT}_{7}$ receptors. ${ }^{31}$ It is still not conclusively known, however, whether and to what extent these actions contribute to therapeutic effects. Other potential roles for the $5-\mathrm{HT}_{7}$ receptor include regulation of circadian rhythms ${ }^{28}$ and sleep, ${ }^{32}$ thermoregulation, ${ }^{33-35}$ learning and memory, ${ }^{36,37}$ and endocrine regulation. $^{38,39}$

\section{GLUTAMATERGIC TARGETS}

In recent years, glutamate has attained a key theoretical role in the pathophysiology of schizophrenia. One hypothesis of schizophrenia suggests that early in the 
illness, excessive glutamate activity could lead to excitotoxicity, which might interfere with normal neurodevelopment and be linked to disease progression. However, it is now also widely hypothesized that once schizophrenia has developed, ionotropic N-methyl-D-aspartate (NMDA) glutamate receptors are actually hypofunctional. In any event, a multiplicity of glutamatergic receptors has provided a number of potential therapeutic targets from which to choose. The question of whether to use glutamate agonists or antagonists, however, is not a simple one to answer, and may depend on what stage of the disease is being treated and what symptoms are being targeted. ${ }^{2}$ For example, antagonists of the NMDA receptor block the opening of the NMDA-coupled channel; in principle, this action has the potential to produce a neuroprotective effect by blocking excitotoxic downstream neurotransmission. ${ }^{2}$ The consequences of this blockade, however, are complex and depend on the location of the NMDA receptor. For example, the blockade of NMDA receptors located postsynaptically on cortical GABA interneurons prevents the release of inhibitory GABA from the interneuron, which may result in the disinhibition of downstream glutamatergic neurons. In this instance, the action of an NMDA antagonist (e.g., ketamine) blocks glutamate receptors and yet increases glutamate release. This action has the potential short-term benefit of "rebooting" cortical glutamate regulation in patients with treatment-resistant depression; however, the same action also poses the risk of interfering with prefrontal cortical functioning and, over time, causing symptoms similar to the positive and negative symptoms of schizophrenia. ${ }^{2}$

Complicating this scenario is the fact that glutamatergic neurons also modulate dopaminergic neurotransmission. In the mesolimbic pathway, a descending cortico-brainstem glutamate pathway acts as a brake on dopamine release through an inhibitory GABA interneuron in the ventral tegmental area. NMDA hypoactivation in this circuit may therefore result in dopamine hyperactivity and give rise to positive symptoms of schizophrenia. ${ }^{40}$ Similarly, blockade of NMDA receptors on glutamatergic neurons that synapse directly on dopaminergic neurons in the mesocortical pathway may produce dopamine hypoactivity in the dorsolateral and ventromedial prefrontal cortices, leading to negative, affective, and cognitive symptoms. ${ }^{40}$ These mechanisms have given rise to the theory that NMDA receptors may be pathologically hypofunctional in untreated schizophrenia, similar to the effects produced by psychotomimetic agents such as phencyclidine and ketamine. ${ }^{41,42}$ The use of direct agonists of NMDA receptors to rectify NMDA hypoactivity, however, may not be clinically feasible because of the aforementioned risk of excess excitation of NMDA-coupled channels and resulting neurotoxicity. ${ }^{19}$

Another class of glutamate receptors known as metabotropic glutamate receptors (mGluR) regulates neurotransmission at glutamate synapses. Agents that act as agonists at presynaptic mGluR2 and mGluR3 (group II) autoreceptors may reduce glutamate release and be potentially useful as anticonvulsants and mood stabilizers, in addition to being neuroprotective against glutamate neurotoxicity. ${ }^{2}$ Group II mGluR have also been linked to attenuation of cognitive symptoms, such as deficits in working memory. ${ }^{43}$ A possible limitation to mGluR as a therapeutic target, however, is the suggestion that group II receptors may desensitize during chronic treatment. ${ }^{44}$

\section{GLYCINE AGONISTS}

Much of the current targeting of the glutamate system in schizophrenia is aimed at increasing glutamatergic neurotransmission to compensate for NMDA hypoactivation. The challenge is to do so without producing neurotoxic effects; pharmacologic therapies for schizophrenia that involve direct enhancement of glutamate run the risk of excitotoxicity if glutamatergic neurotransmission becomes excessive. ${ }^{2}$ A potentially safer way to enhance glutamate is to exploit the fact that NMDA glutamate receptors require allosteric binding by glycine. ${ }^{45}$ In addition to glycine itself, the glycine site of the NMDA receptor also binds the endogenous agonist D-serine, ${ }^{46}$ the partial agonist D-cycloserine, ${ }^{47,48}$ and D-alanine. ${ }^{49}$ These coagonists appear to modulate, but not activate, the NMDA receptor, and therefore seem to be free of excitotoxic effects associated with glutamate. ${ }^{50}$ Smallscale clinical trials of these agents in the treatment of schizophrenia have begun, and some evidence has emerged that glycine agonists may be able to reduce negative and/or cognitive symptoms. Of the four agents, D-cycloserine has been the least promising, possibly due to its partial agonism and the fact that it acts as an antagonist at high $(100 \mathrm{mg})$ doses. ${ }^{51}$

Another proposed approach to rectifying NMDA hypoactivity via glycine allosterism involves the glial glycine transporter GLYT1, which is a reuptake pump that terminates the synaptic action of glycine by shuttling glycine back into glial cells; inhibition of this transporter should theoretically increase the synaptic availability of glycine, thus enhancing NMDA neurotransmission. ${ }^{52}$ In this manner, GLYT1 inhibitors are analogous to drugs that inhibit reuptake of other neurotransmitters, such as serotonin selective reuptake inhibitors. ${ }^{53}$ Several GLYT1 inhibitors are now in clinical or preclinical testing, including the natural agent $\mathrm{N}$-methyl-glycine (also known as sarcosine).

\section{LEARNING FROM SIDE EFFECTS}

In addition to dopaminergic, serotonergic, and glutamatergic effects, antipsychotics typically block a number 
of other receptors, including muscarinic cholinergic, histaminic, and adrenergic receptors. Blockade of these receptors can give rise to certain undesirable side effects: constipation, blurred vision, dry mouth, sedation, and cognitive dysfunction (via $\mathrm{M}_{1}$ muscarinic cholinergic receptors); weight gain and sedation (via $\mathrm{H}_{1}$ histaminic receptors); and orthostatic hypotension and sedation (via $\alpha_{1}$ adrenergic receptors). ${ }^{2}$ If antagonism of these receptors causes side effects, it is germane to the discussion of therapeutic design to ask whether the action of agonists at these same receptors might have therapeutic effects. This method has already been followed by researchers looking for new therapeutic targets in schizophrenia. For example, the major active metabolite of clozapine, $\mathrm{N}$ desmethylclozapine, has been reported to be a potent $M_{1}$ agonist and dopamine partial agonist with the ability to potentiate hippocampal NMDA activity as well. ${ }^{54,55}$ As a result of these findings, N-desmethylclozapine (ACP104) and other $M_{1}$ receptor agonists are in clinical trials as potential treatments of the cognitive dysfunction of schizophrenia. $^{22}$

\section{CONCLUSION}

The "return" to therapeutic strategies for schizophrenia that exploit the pharmacological multifunctionality of antipsychotics has been the rational outcome of our improved understanding of the disease. As is the case for other psychiatric disorders, the various symptoms of schizophrenia are now recognized to be not only localized in unique regions of the brain, but mediated by specific receptor sites as well. Therefore, treating the broad spectrum of symptoms of schizophrenia needs to be viewed as an endeavor to treat the whole brain. To optimize and individualize treatments to address the unique symptoms of each patient, it is important to consider which symptoms are being expressed, and therefore which areas of the brain are hypothetically malfunctioning. ${ }^{2}$ Each brain region has characteristic neurotransmitters, receptors, enzymes, and genes that regulate its activity, with substantial overlap and communication occurring with other brain regions. A solid understanding of these interrelationships can help the clinician in choosing appropriate medications that will address the specific needs of the patient. Once a therapeutic agent or agents have been selected, it will furthermore be essential to remember that, in general, multifunctional drugs do not have the same potencies at each of their functions, and as we have seen with aripiprazole, they may actually be very different drugs at low doses versus high doses. Dosage must therefore be adjusted properly to take full advantage of the pharmacological receptor profile of the antipsychotic and to achieve the therapeutic goals. When successful, this approach will provide a total therapeutic response that is greater than the sum of its parts.
Acknowledgments: We thank Daniel Lara Rios for figure preparation, and Sharon Tyndall and Ryan Todoroff for their preliminary review of the manuscript.

\section{REFERENCES}

1. Kirkpatrick B, Fenton WS, Carpenter WT Jr., Marder SR. The NIMH-MATRICS consensus statement on negative symptoms. Schizophr Bull 2006;32:214-219.

2. Stahl SM. Stahl's essential psychopharmacology: neuroscientific basis and practical applications, 3rd ed. New York: Cambridge University Press, 2008.

3. Strange PG. Antipsychotic drug action: antagonism, inverse agonism or partial agonism. Trends Pharmacol Sci 2008;29:314-321.

4. Kapur S, Seeman P. Does fast dissociation from the dopamine $\mathrm{D}_{2}$ receptor explain the action of atypical antipsychotics? A new hypothesis. Am J Psychiatry 2001;158:360-369.

5. Miyamoto S, Duncan GE, Marx CE, Lieberman JA. Treatments for schizophrenia: a critical review of pharmacology and mechanisms of action of antipsychotic drugs. Mol Psychiatry 2005;10:79-104.

6. Meltzer HY. What's atypical about atypical antipsychotic drugs? Curr Opin Pharmacol 2004;4:53-57.

7. Schmidt AW, Lebel LA, Howard HR Jr., Zorn SH. Ziprasidone: a novel antipsychotic agent with a unique human receptor binding profile. Eur J Pharmacol 2001;425:197-201.

8. Stahl SM. Do dopamine partial agonists have partial efficacy as antipsychotics? CNS Spectr 2008;13:279-282.

9. Burris KD, Molski TF, Xu C, et al. Aripiprazole, a novel antipsychotic, is a high-affinity partial agonist at human dopamine $\mathrm{D}_{2}$ receptors. J Pharmacol Exp Ther 2002;302:381-389.

10. Carlsson A, Waters N, Carlsson ML. Neurotransmitter interactions in schizophrenia-therapeutic implications. Biol Psychiatry 1999; 46:1388-1395.

11. Lawler CP, Prioleau C, Lewis MM, et al. Interactions of the novel antipsychotic aripiprazole (OPC-14597) with dopamine and serotonin receptor subtypes. Neuropsychopharmacology 1999;20:612627.

12. Mamo D, Graff A, Mizrahi R, Shammi CM, Romeyer F, Kapur S. Differential effects of aripiprazole on $\mathrm{D}_{2}, 5-\mathrm{HT}_{2}$, and $5-\mathrm{HT}_{1 \mathrm{~A}}$ receptor occupancy in patients with schizophrenia: a triple tracer PET study. Am J Psychiatry 2007;164:1411-1417.

13. Berman RM, Marcus RN, Swanink R, et al. The efficacy and safety of aripiprazole as adjunctive therapy in major depressive disorder: a multicenter, randomized, double-blind, placebo-controlled study. J Clin Psychiatry 2007;68:843-853.

14. Thase ME, Jonas A, Khan A, et al. Aripiprazole monotherapy in nonpsychotic bipolar I depression: results of 2 randomized, placebo-controlled studies. J Clin Psychopharmacol 2008;28:13-20.

15. Ichikawa J, Ishii H, Bonaccorso S, Fowler WL, O'Laughlin IA, Meltzer HY. 5- $\mathrm{HT}_{2 \mathrm{~A}}$ and $\mathrm{D}_{2}$ receptor blockade increases cortical DA release via $5-\mathrm{HT}_{1 \mathrm{~A}}$ receptor activation: a possible mechanism of atypical antipsychotic-induced cortical dopamine release. J Neurochem 2001;76:1521-1531.

16. Azmitia EC, Gannon PJ, Kheck NM, Whitaker-Azmitia PM. Cellular localization of the $5-\mathrm{HT}_{1 \mathrm{~A}}$ receptor in primate brain neurons and glial cells. Neuropsychopharmacology 1996;14:35-46.

17. Sumiyoshi T, Matsui M, Nohara S, et al. Enhancement of cognitive performance in schizophrenia by addition of tandospirone to neuroleptic treatment. Am J Psychiatry 2001;158:1722-1725.

18. Yasuno F, Suhara T, Nakayama T, et al. Inhibitory effect of hippocampal 5- $\mathrm{HT}_{1 \mathrm{~A}}$ receptors on human explicit memory. Am J Psychiatry 2003;160:334-340.

19. Gray JA, Roth BL. Molecular targets for treating cognitive dysfunction in schizophrenia. Schizophr Bull 2007;33:1100-1119.

20. Alex KD, Pehek EA. Pharmacologic mechanisms of serotonergic regulation of dopamine neurotransmission. Pharmacol Ther 2007; 113:296-320.

21. Millan MJ, Dekeyne A, Gobert A. Serotonin $(5-H T)_{2 C}$ receptors tonically inhibit dopamine (DA) and noradrenaline (NA), but not $5-\mathrm{HT}$, release in the frontal cortex in vivo. Neuropharmacology 1998;37:953-955.

22. Gray JA, Roth BL. The pipeline and future of drug development in schizophrenia. Mol Psychiatry 2007;12:904-922. 
23. Alex KD, Yavanian GJ, McFarlane HG, Pluto CP, Pehek EA. Modulation of dopamine release by striatal $5-\mathrm{HT}_{2 \mathrm{C}}$ receptors. Synapse 2005;55:242-251.

24. Gunes A, Dahl ML, Spina E, Scordo MG. Further evidence for the association between $5-\mathrm{HT}_{2 \mathrm{C}}$ receptor gene polymorphisms and extrapyramidal side effects in male schizophrenic patients. Eur J Clin Pharmacol 2008;64:477-482.

25. Reavill C, Kettle A, Holland V, Riley G, Blackburn TP. Attenuation of haloperidol-induced catalepsy by a $5-\mathrm{HT}_{2 \mathrm{C}}$ receptor antagonist. Br J Pharmacol 1999;126:572-574.

26. Stahl SM. Novel mechanism of antidepressant action: norepinephrine and dopamine disinhibition (NDDI) plus melatonergic agonism. Int J Neuropsychopharmacol 2007;10:575-578.

27. Bard JA, Zgombick J, Adham N, Vaysse P, Branchek TA, Weinshank RL. Cloning of a novel human serotonin receptor $\left(5-\mathrm{HT}_{7}\right)$ positively linked to adenylate cyclase. J Biol Chem 1993;268: 23422-23426.

28. Lovenberg TW, Baron BM, de LL, et al. A novel adenylyl cyclaseactivating serotonin receptor $\left(5-\mathrm{HT}_{7}\right)$ implicated in the regulation of mammalian circadian rhythms. Neuron 1993;11:449-458.

29. Ruat M, Traiffort E, Leurs R, et al. Molecular cloning, characterization, and localization of a high-affinity serotonin receptor (5$\mathrm{HT}_{7}$ ) activating cAMP formation. Proc Natl Acad Sci USA 1993; 90:8547-8551.

30. Mullins UL, Gianutsos G, Eison AS. Effects of antidepressants on $5-\mathrm{HT}_{7}$ receptor regulation in the rat hypothalamus. Neuropsychopharmacology 1999;21:352-367.

31. Roth BL, Craigo SC, Choudhary MS, et al. Binding of typical and atypical antipsychotic agents to 5-hydroxytryptamine-6 and 5-hydroxytryptamine-7 receptors. J Pharmacol Exp Ther 1994;268: $1403-1410$

32. Thomas DR, Melotto S, Massagrande M, et al. SB-656104-A, a novel selective 5- $\mathrm{HT}_{7}$ receptor antagonist, modulates REM sleep in rats. Br J Pharmacol 2003;139:705-714.

33. Guscott MR, Egan E, Cook GP, et al. The hypothermic effect of 5 -CT in mice is mediated through the $5-\mathrm{HT}_{7}$ receptor. Neuropharmacology 2003;44:1031-1037.

34. Hagan JJ, Price GW, Jeffrey P, et al. Characterization of SB269970-A, a selective 5- $\mathrm{HT}_{7}$ receptor antagonist. Br J Pharmacol 2000;130:539-548.

35. Hedlund PB, Danielson PE, Thomas EA, Slanina K, Carson MJ, Sutcliffe JG. No hypothermic response to serotonin in $5-\mathrm{HT}_{7}$ receptor knockout mice. Proc Natl Acad Sci USA 2003;100:13751380.

36. Manuel-Apolinar L, Meneses A. 8-OH-DPAT facilitated memory consolidation and increased hippocampal and cortical cAMP production. Behav Brain Res 2004;148:179-184.

37. Roberts AJ, Krucker T, Levy CL, Slanina KA, Sutcliffe JG, Hedlund $\mathrm{PB}$. Mice lacking 5- $\mathrm{HT}_{7}$ receptors show specific impairments in contextual learning. Eur J Neurosci 2004;19:1913-1922.

38. Jorgensen H, Riis M, Knigge U, Kjaer A, Warberg J. Serotonin receptors involved in vasopressin and oxytocin secretion. J Neuroendocrinol 2003;15:242-249.
39. Laplante P, Diorio J, Meaney MJ. Serotonin regulates hippocampal glucocorticoid receptor expression via a $5-\mathrm{HT}_{7}$ receptor. Brain Res Dev Brain Res 2002;139:199-203.

40. Stahl SM. Beyond the dopamine hypothesis to the NMDA glutamate receptor hypofunction hypothesis of schizophrenia. CNS Spectr 2007;12:265-268.

41. Newcomer JW, Farber NB, Jevtovic-Todorovic V, et al. Ketamineinduced NMDA receptor hypofunction as a model of memory impairment and psychosis. Neuropsychopharmacology 1999;20: $106-118$.

42. Olney JW, Newcomer JW, Farber NB. NMDA receptor hypofunction model of schizophrenia. J Psychiatr Res 1999;33:523-533.

43. Moghaddam B, Adams BW. Reversal of phencyclidine effects by a group II metabotropic glutamate receptor agonist in rats. Science 1998;281:1349-1352.

44. Javitt DC. Glutamate as a therapeutic target in psychiatric disorders. Mol Psychiatry 2004;9:984-997.

45. Johnson JW, Ascher P. Glycine potentiates the NMDA response in cultured mouse brain neurons. Nature 1987;325:529-531.

46. Mothet JP, Parent AT, Wolosker H, et al. D-serine is an endogenous ligand for the glycine site of the N-methyl-D-aspartate receptor. Proc Natl Acad Sci USA 2000;97:4926-4931

47. Goff DC, Herz L, Posever T, et al. A six-month, placebo-controlled trial of D-cycloserine co-administered with conventional antipsychotics in schizophrenia patients. Psychopharmacology (Berl) 2005;179:144-150.

48. Heresco-Levy U, Javitt DC. Comparative effects of glycine and D-cycloserine on persistent negative symptoms in schizophrenia: a retrospective analysis. Schizophr Res 2004;66:89-96.

49. Tsai GE, Yang P, Chang YC, Chong MY. D-alanine added to antipsychotics for the treatment of schizophrenia. Biol Psychiatry 2006;59:230-234.

50. Javitt DC. Is the glycine site half saturated or half unsaturated? Effects of glutamatergic drugs in schizophrenia patients. Curr Opin Psychiatry 2006;19:151-157.

51. van Berckel BN, Evenblij CN, van Loon BJ, et al. D-cycloserine increases positive symptoms in chronic schizophrenic patients when administered in addition to antipsychotics: a double-blind, parallel, placebo-controlled study. Neuropsychopharmacology 1999;21:203-210.

52. Bergeron R, Meyer TM, Coyle JT, Greene RW. Modulation of $\mathrm{N}$-methyl-D-aspartate receptor function by glycine transport. Proc Natl Acad Sci USA 1998;95:15730-15734.

53. Stahl SM. Novel therapeutics for schizophrenia: targeting glycine modulation of NMDA glutamate receptors. CNS Spectr 2007;12: 423-427.

54. Burstein ES, Ma J, Wong S, et al. Intrinsic efficacy of antipsychotics at human $\mathrm{D}_{2}, \mathrm{D}_{3}$, and $\mathrm{D}_{4}$ dopamine receptors: identification of the clozapine metabolite $\mathrm{N}$-desmethylclozapine as a $\mathrm{D}_{2} / \mathrm{D}_{3}$ partial agonist. J Pharmacol Exp Ther 2005;315:1278-1287.

55. Sur C, Mallorga PJ, Wittmann M, et al. N-desmethylclozapine, an allosteric agonist at muscarinic 1 receptor, potentiates $\mathrm{N}$-methylD-aspartate receptor activity. Proc Natl Acad Sci USA 2003;100: 13674-13679. 